\title{
GAMES IN ENVIRONMENTAL SUSTAINABILITY EDUCATION
}

\author{
Shamila Janakiraman, Visiting Faculty, Purdue University, sjanakir@purdue.edu
}

\section{Concept and Research Questions (Abstract)}

Sustainability education must not stop with creating awareness, it should promote mindfulness, be persuasive, and also adapt to the needs of young learners (Janakiraman et al., 2018). Knowledge, when provided as an activity and experience that is situated in scenarios, will help learners develop situated understandings (Gee, 2008). In environmental sustainability education (ESE), digital games can serve as effective pedagogical tools because they can encourage exploration and experimentation when teachers and parents use them purposefully. This brief examines the following questions: (a) Were there any differences in the environmental attitudes between students who played a game and students who did not play the game based on the New Ecological Paradigm scale? (b) What were the perceptions of participants who played the game regarding their environmental attitudes and behaviors?

\section{Methodology and Findings}

This mixed-methods research study was conducted in a high school in India. It employed a convergent mixed-methods approach, where one group of students played a game designed for ESE called EnerCities, while the control group did not play any game. All participants had studied ESE from elementary school. The game used in the study addresses the content standard Env.1.2 in the Indiana Environmental Science standards: Understand and explain that human beings are part of Earth's ecosystems and give examples of how human activities can, deliberately or inadvertently, alter ecosystems. A survey based on the New Ecological Paradigm (NEP; Dunlap et al., 2000) scale was used to collect quantitative data. Qualitative data was collected through interviews with students who played the game after the survey was administered.

The quantitative results from this study found that EnerCities had significantly impacted the environmental attitudes of the Game group compared to the control group that did not play EnerCities. Both the uni-dimensional and multi-dimensional properties of the NEP scale were considered. Thematic analysis of the interview data provided insights into the Game group participants' perceptions about their environmental attitudes and behaviors before and after playing the game. The goal of ESE is to make learners realize that, "Many of today's environmental problems such as global warming, species collapse, and ozone depletion can be attributed to human activity" (Cordano et al., 2003). This was achieved using EnerCities, along with minimal instructional support.

\section{References}

Cordano, M., Welcomer, S. A., \& Scherer, R. F. (2003). An analysis of the predictive validity of the new ecological paradigm scale. The Journal of Environmental Education, 34(3), 22-28.

Dunlap, R. E., Van Liere, K. D., Mertig, A. G., \& Jones, R. E. (2000). New trends in measuring environmental attitudes: measuring endorsement of the new ecological paradigm: a revised NEP scale. Journal of Social Issues, 56(3), 425-442.

Gee, J. (2008). Game-like learning. In P. Moss, D. Pullin, J. Gee, E. Haertel, \& L. Young (Eds.), Assessment, equity, and opportunity to learn (Learning in doing: Social, cognitive, and computational perspectives) (pp. 200221). Cambridge: Cambridge University Press. doi:10.1017/CBO9780511802157.010

Janakiraman, S., Watson, S. L., \& Watson, W. R. (2018). Using game-based learning to facilitate attitude change for environmental sustainability. Journal of Education for Sustainable Development, 12(2), 176-185. 